\title{
Functional abdominal pain, psychiatric illness, and life events
}

\author{
F CREED, T CRAIG, AND R FARMER \\ From the Dept of Psychiatry, University of Manchester, Manchester, and Dept of Social Policy and Social \\ Science, Bedford College, University of London, London.
}

SUMMARY Patients undergoing appendicectomy, attending a gastroenterology clinic or admitted to hospital after self-poisoning have been examined using the same reliable measures to establish whether life events and psychiatric illness preceded abdominal pain. Life events involving threat were experienced more commonly by those with organic and functional abdominal illness, compared with community comparison subjects. The greatest difference was with severe events, especially those involving the break-up of close relationships, which preceded the development of functional abdominal pain as often as they occurred before self-poisoning, and significantly more frequently than before the onset of organic gastrointestinal illness. Abdominal pain of recent onset, for which no organic cause is found, is often preceded by environmental stress, whether it presents to the surgeon or the physician. Those presenting in the clinic were older than those undergoing appendicectomy and had experienced more long lasting interpersonal difficulties. Many had psychiatric illness, but for the remainder the stress might either have caused colonic pain directly or led to consultation for abdominal pains that had not previously presented to a gastroenterologist.

The largest single category of patients attending gastroenterology clinics are described as suffering from complaints for which no structural pathology can be shown.' Swarbrick and colleagues ${ }^{2}$ indicated that distension of the colon may cause such abdominal pain and argue against a prolonged search for intra-abdominal pathology in these patients. But a complete explanation for the origin of such pain requires systematic study of all aetiological factors. Although some form of neurotic illness has been repeatedly blamed for the presentation of such symptoms, methodological difficulties have so far prevented a firm conclusion on this issue. ${ }^{3}$

Previous studies have generally used self-rating questionnaires of personality traits or neurotic symptoms and such instruments cannot provide a definite diagnosis of psychiatric illness. ${ }^{4}$ Research interviews have now shown that patients suffering from non-organic gastrointestinal illness are twice as

Address for correspondence: Dr Francis Creed, Department of Psychiatry, Rawnsley Building, Manchester Royal Infirmary, Oxford Road, Manchester M13 9WL.

Received for publication 14 August 1987 likely as those with organic illness to be suffering from psychiatric illness, ${ }^{5}$ and nearly half of those with severe functional bowel disorder have been shown to have moderate or severe depressive illness. ${ }^{6}$ Such studies have not shown whether the psychiatric illness or the bowel disturbance occured first. So a clear demonstration that the onset of psychiatric illness and the experience of threatening life events precede the onset of bowel disturbance is required to show that the psychiatric disorder is not simply a reaction to prolonged bowel disturbance.

We report here the results of three separate studies which measured psychiatric symptoms and life events using the same reliable instruments. ${ }^{78}$ In each case the aim of the study was to examine whether life events had occurred before the onset of an illness more frequently than expected by chance. The findings of these studies provide a more complete understanding of the relationship between psychosocial factors and the onset of functional bowel disturbance than has previously been possible.

The first study concerned patients undergoing appendicectomy, ${ }^{9}$ who were ideally suited to a study 
of life events because they had a recent onset of abdominal pain which can be accurately dated. Some patients proved to have definite acute appendicitis but the remainder were diagnosed as suffering from non-specific abdominal pain. ${ }^{10}$

The second study ${ }^{11}$ used patients attending a gastroenterology clinic who had a clear onset or recurrence of abdominal pain within one year of the clinic attendance.

The third study 12 involved patients who were admitted to hospital having taken an overdose. These patients are well known to have undergone recent crises and are included in the present report to illustrate the similarity between the life changes preceding the onset of functional bowel disturbance and those preceding self-poisoning. The appendicectomy and self-poisoning patients were comparable in terms of age and sex; the clinic patients were older and therefore required their own community comparison group. The results are presented together to show those environmental stresses which precede onset of abdominal pain, for which no organic cause can be found, whether it is acute and presents to a surgeon or less acute and presents in a gastroenterology clinic.

\section{Methods}

\section{PATIENT SELECTION}

The appendicectomy sample formed a consecutive series of patients (aged 17-30 years) undergoing appendicectomy at three hospitals, excluding those who were found to have some organic cause for their abdominal pain other than appendicitis. ${ }^{9}$ The community comparison subjects were selected from the roll of a local borough council and matched for age, sex and social class to the appendicectomy subjects.

In the second study" patients between the ages of 18 and 60 years were selected from a consecutive series of attenders at three gastroenterology clinics. Each patient had developed abdominal pain within the previous 12 months. For many this was their first episode of such pain; for those with a recurrence, patients were included only if their first ever episode of abdominal pain had been within three years and they had been free of pain for at least a year without medication before the present episode. All patients were interviewed before the completion of any physical investigations usually at the first clinic attendance.

A comparison group that had been free of gastrointestinal illness for at least two years was selected from a random sample registered at general practices in the catchment areas of the hospital clinics. These comparison subjects were matched with the patient sample on the basis of age, sex, marital state, social class, country of birth and life stage (an index reflecting marital and parental status known to affect frequency of life events).

The self-poisoning patients were a consecutive series of those patients (aged 17-35 years) admitted to medical wards of a district hospital, and who remained for the routine psychiatric assessment to be made. Their age and sex distribution was similar to that of the appendicectomy group so results of the self-poisoning subjects have been compared with those of the appendicectomy community comparison group.

\section{MEASUREMENT OF LIFE EVENTS}

The life event and difficulties schedule (LEDS $\left.{ }^{7}\right)$ formed the basis of the life event component of the research interview in each of the three studies reported here. This instrument is of known reliability, when used by a trained interviewer. In each study the subject was interviewed regarding the year before the onset of abdominal pain, the deliberate self-harm, or the date of the interview in the case of the community comparison groups. The interviewer thus ascertained the occurrence and precise timing of any discrete event or chronic environmental stressor.

In the LEDS system only events affecting the subject, first degree relatives, household members or named confidants are considered for inclusion. Each category of likely event is precisely defined before the investigation - for example, being off work with illness can only be considered if it concerns one of the individuals listed above and if it lasts at least four weeks; an interaction change only if the person leaving has been a household member for at least three months.

In addition to discrete changes, the LEDS also measures chronic social stressors. These are recorded as chronic difficulties and, like events, have to fulfil specific inclusion criteria.

If a life event or chronic difficulty fulfils the criteria for inclusion, the LEDS also rates it on a number of qualitative dimensions. The most important of these is the degree to which the event or difficulty can be considered to be threatening to the subject. In the LEDS system, the contextual threat is a measure of how distressing or unpleasant the average person would find such an event given similar biographical and current circumstances. This rating is made for the immediate impact of the event (short term threat) and for any longterm implications thereafter (longterm threat). Thus a close relative admitted to hospital as an emergency with a suspected myocardial infarct would score 1 or 2 on short term threat. At the end of the week, if he has been discharged fit with the diagnosis having been changed to a less serious illness, the longterm rating would 
probably be 4 ; but if he remains in hospital with continuing pain or complications the longterm threat would be 1 or 2 .

To avoid contamination by a subject's disturbed emotional state, the rating of threat is made by a research group who are provided only with the appropriate objective details of the event and not the subject's reaction to it. These raters are blind to which group the subject belongs (organic, functional or comparison). For example, a woman may be extremely distressed after the break-up of a close relationship with a boy friend. The degree of distress might indicate this was a severely threatening event; but the research group rate the event independent of this emotional response. If the objective facts indicate that the relationship had only lasted a few weeks and there had been no clear evidence of intended permanency this event would not be rated as severe ( 1 or 2$)$ in the long term (although the circumstances might warrant a short term rating of 1 or 2 if a degree of shock was involved). Without this procedure the erroneous conclusion could be reached that severe life events occured more frequently before self-poisoning or the onset of functional abdominal pain simply because many of these people were distressed at the time of the interview.

Marked chronic difficulties are those stressors which are present for months or years and which carry a similar degree of unpleasantness or threat to the individual. A marital difficulty would be scored as 1-3 on a seven point scale if the evidence of arguments, separations or extramarital relationships seem to the research group to indicate probable or likely break-up of the marriage. (For fuller details of the method see refs 7,9 or 11 .)

\section{PSYCHIATRIC DISORDER}

Information on recent psychiatric symptoms was obtained by means of the Present State Examination. ${ }^{8}$ The interview concerns symptoms experienced during the previous month but considerable effort was made to date the onset of psychiatric symptoms, where applicable, within the previous year. There are different thresholds of defining a 'case' of psychiatric illness, the one used in these studies is that which generally indicates the need for psychiatric treatment.

\section{PHYSICAL DIAGNOSIS}

After all the interviews were completed, and the LEDS and any psychiatric disorder had been rated for patients and community subjects, the details of the physical diagnosis were obtained. In the appendicectomy study these were provided by an independent pathologist's report of the histological appearance of the removed organ. These were categorised as 'definite acute appendicitis' and 'not acutely inflamed'. For the gastroenterology patients, diagnosis was provided by the physician on the basis of investigation results; subjects being classified as 'organic' where there was confirmatory evidence of disease - for example, endoscopically visualised active peptic ulceration, or as 'functional' when no structural pathology could be shown to account for the symptoms. In both studies physical diagnoses were made blind to the results of the research interview. Life event results are expressed as the proportion of subjects who have experienced an event of a particular type in a given time period. Thirty eight weeks is the time period used in most research using the LEDS because this time is important in the aetiology of depression. This time period is long enough to include those severe events, such as bereavement, that may affect the individual for some months, but not so long that distorted data might result from poor recall.

STATISTICAL ANALYSIS

Statistical significance of differences between groups has been assessed using the $\chi^{2}$ test.

\section{Results}

The demographic details of the samples are shown in Table 1. The subjects in the gastroenterology clinic were older (reflecting the selection criteria); and were more often married (and separated/divorced) than those undergoing appendicectomy. In both studies those with functional abdominal pain included more women whereas in the organic illness groups there was a slight predominance of men. There were no significant differences between the demographic characteristics of the subjects in the self-poisoning group and those of the community comparison group for the appendicectomy study.

The commonest diagnoses in the gastroenterology

Table 1 Demographic characteristics

\begin{tabular}{lclll}
\hline & $n$ & $\begin{array}{l}\text { Women } \\
\%\end{array}$ & $\begin{array}{l}\text { Mean age } \\
(y r s)\end{array}$ & $\begin{array}{l}\text { Single } \\
\%\end{array}$ \\
\hline Gastro-Clinic: & & & & \\
$\begin{array}{l}\text { Organic } \\
\text { Functional }\end{array}$ & 56 & 48 & 38 & $22^{*}$ \\
Comparison & 79 & 73 & 34 & $40^{*}$ \\
Appendicectomy & 135 & 63 & 36 & 33 \\
Acutely inflamed & & & & \\
Not acutely inflamed & 63 & 38 & 22 & $68^{*}$ \\
Comparison & 56 & 82 & 22 & $73^{*}$ \\
Deliberate self-harm & 62 & 61 & 22 & 61 \\
\hline
\end{tabular}

$* 33 \%$ of the patients attending the gastroenterology clinic were single compared with $70 \%$ of the appendicectomy patients $p<0 \cdot 001$. 
clinic sample were peptic ulcer $(41 \%)$ for the organic group; irritable bowel syndrome $(35 \%)$, dyspepsia $(18 \%)$ and abdominal pain $(44 \%)$ for the functional group. Twenty eight of the 135 patients included in that study had recurrences of a previous disorder (15 organic and 13 functional). For convenience hereafter 'organic' refers to organic gastroenterology clinic patients and acute appendicitis patients, whereas 'functional' refers to the remaining clinic patients and those with a not acutely inflamed appendix.

All the groups considered were similar in the proportion who had experienced any kind of life event over the previous 38 weeks (Fig. 1). But, compared with the community comparison groups, a significantly greater proportion of all the patient groups had experienced an event which involved some threat to the subject $(\mathrm{p}<0.05$ for the organic illness groups and $p<0.001$ for the functional groups - Fig. 2). Common examples of this type of event were: enforced changes at work, housing crises, contact with the police and loss of close interpersonal ties.

The pattern was different when only those events

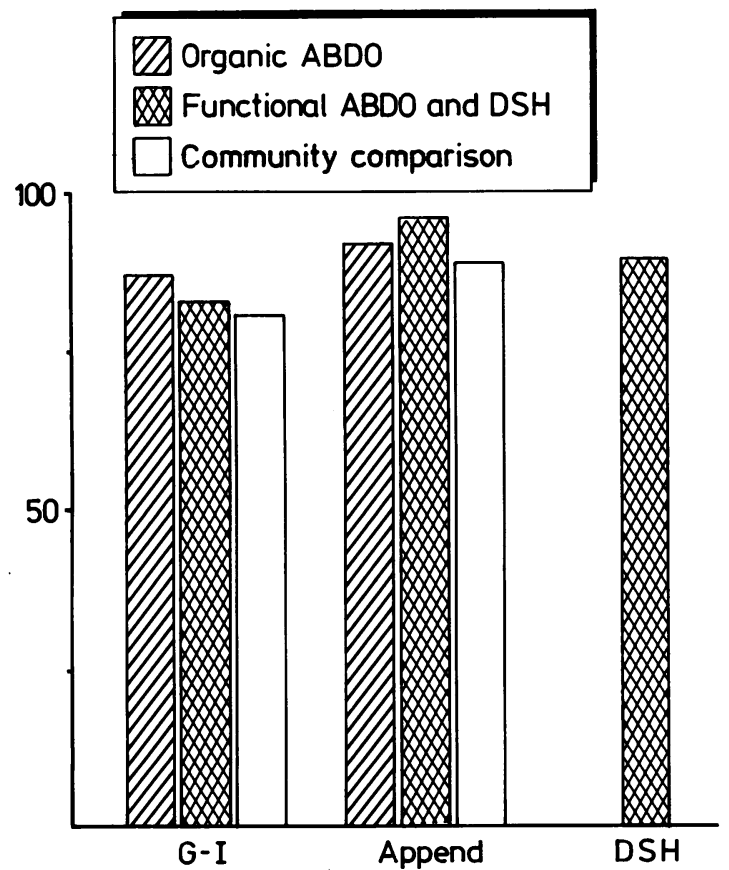

Fig. 1 Proportion of subjects (as percentage) experiencing a life event during 38 weeks before onset of abdominal pain, self-poisoning, or interview in the case of community subjects. $(G-I=$ patients attending gastroenterology clinic; Append = patients undergoing appendicectomy; $D S H=$ deliberate self-harm). which are severely threatening in the long term were considered (severe events). These events included separation from spouse or long standing girl/ boyfriend, divorce, court appearance with threat of imprisonment and deaths in the family; events which are known to be related to the onset of depressive illness. It was the functional abdominal pain groups that had experienced these severe events in a proportion similar to the self-poisoning population and significantly greater than either the organic $(p<0 \cdot 01)$ or healthy comparison $(\mathrm{p}<0.0001)$ groups (Fig. 3$)$. Analysis by sex did not affect these findings. The high rate of severe events is very similar to that found in depressed patients.?

The most frequent type of severe event in the case of the functional abdominal pain group involved a major disruption of close relationships; a marital separation, a family member leaving home, or breakup of a serious girl/boyfriend relationship (interaction events - Table 2). This contrasted sharply with the organic illness and healthy comparison groups, in which serious illnesses and hospital admissions of family members were the most frequent severe events.

The results concerning marked chronic difficulties showed a similar pattern (Table 3 ). When all marked

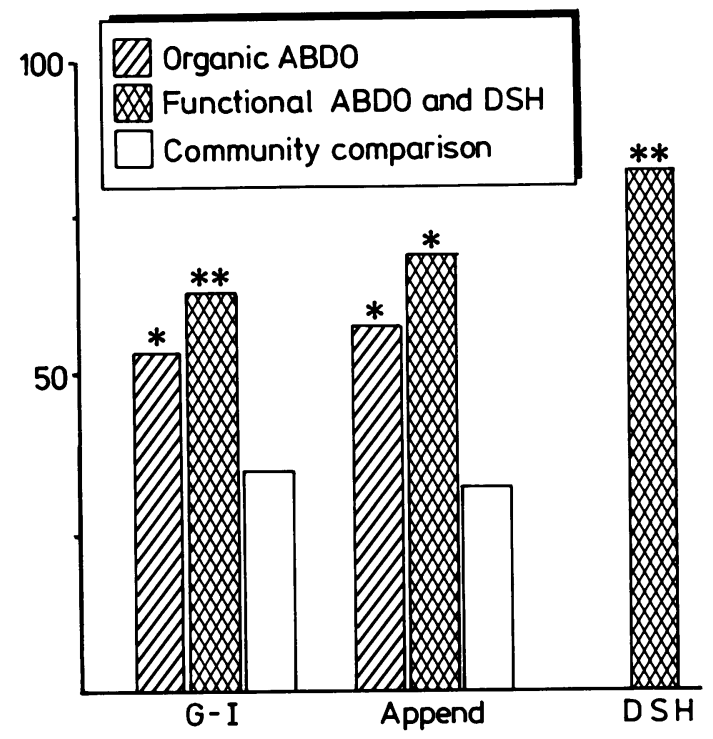

Fig. 2 Proportion of subjects (as \%) experiencing a threatening life event during 38 weeks before onset of abdominal pain, self-poisoning, or interview in the case of community subjects. ( $G-I=$ patients attending gastroenterology clinic; Append = patients undergoing appendicectomy; $\mathrm{DSH}=$ deliberate self-harm.) ${ }^{*} p<0.05$ compared with community comparison group; ${ }^{* *} p<0.001$ compared with community comparison group. 


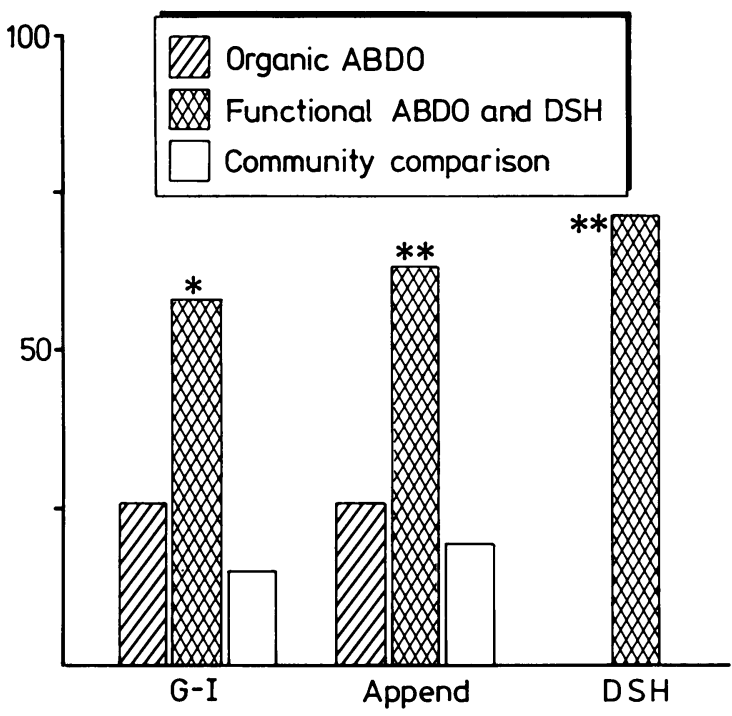

Fig. 3 Proportion of subjects (as \%) experiencing a severe life event during 38 weeks prior to onset of abdominal pain, self-poisoning, or interview in the case of community subjects. $(G-I=$ patients attending gastroenterology clinic; Append=patients undergoing appendicectomy; $\mathrm{DSH}=$ deliberate self-harm.) ${ }^{*} p<0.01$ compared with community comparison group and organic gastrointestinal illness group, ${ }^{* *} p<0.0001$ compared with community comparison group and acute appendicitis group.

difficulties were considered the organic illness groups fell intermediate between the functional and community groups. But when only marked personal relationship difficulties were considered (severe marital problems or extreme family or household tensions) these were much more frequently recorded among the functional abdominal pain groups.

Table 4 indicates the prevalence of psychiatric disorder which definitely occurred before the onset of abdominal pain. Because it is known that the experi-

Table 2 Proportion of subjects with a severe 'interaction' event

\begin{tabular}{llll}
\hline Gastro-Clinic & \multicolumn{2}{l}{ Appendicectomy } & DSH \\
\hline Organic & $5 \%$ & Acutely inflamed & $6 \%$ \\
Functional $28 \% \dagger \ddagger$ & Not acutely inflamed $27 \% * \ddagger$ & $33 \%+$ \\
Comparison $7 \%$ & Comparison & $2 \%$ & \\
\hline
\end{tabular}

${ }^{*} \mathrm{p}<0.001$ compared with community comparison group; ${ }^{+} \mathrm{p}<0 .(00) 1$ compared to community comparison group; $\ddagger p<0 \cdot 01$ compared with organic/ac infl. groups.

An 'interaction' event involves someone moving in to the subjects house or a separation from a close person. Those catcgorised as severely threatening were nearly always marital separations or ending of a long lasting and close girl/boy friend relationship or a major family crisis involving a family member leaving home.
Table 3 Proportion of subjects with a chronic difficulty (marked relationship difficulty in parentheses)

\begin{tabular}{lllll}
\hline \multicolumn{4}{l}{ Gastro-Clinic } & \multicolumn{2}{l}{ Appendicectomy } & DSH \\
\hline Organic & $27 \%$ & Acutely inflamed & $24 \%$ & \\
$(\mathrm{n}=56)$ & $(11 \%)$ & $(\mathrm{n}=63)$ & $(13 \%)$ & $(\mathrm{n}=82)$ \\
Functional & $47 \%$ & Not acutely inflamed $38 \%$ & $32 \%$ \\
$(\mathrm{n}=79)$ & $(38 \%)^{*}$ & $(\mathrm{n}=56)$ & $(30 \%) \dagger$ & $(29 \%) \dagger$ \\
Comparison & $16 \%$ & Comparison & $16 \%$ & \\
& $(4 \%)$ & & $(8 \%)$ & \\
\hline
\end{tabular}

For marked relationship difficulties: ${ }^{*} \mathrm{p}<0.0001$ compared with community comparison group; $\uparrow p<0.01$ compared with community comparison group.

For functional abdominal pain group: $\nmid p<0 \cdot 001$ compared with organic group.

For appendix not acutely inflamed group ${ }^{*} \mathrm{p}<0 \cdot() 2$ compared with acutely inflamed group.

Table 4 Proportion of subjects who have psychiatric illness

\begin{tabular}{|c|c|c|c|c|}
\hline \multicolumn{2}{|c|}{ Gastro-Clinic } & \multicolumn{2}{|l|}{ Appendicectomy } & \multirow[t]{2}{*}{$D S H$} \\
\hline $\begin{array}{l}\text { Organic } \\
(n=56)\end{array}$ & $16 \%$ & $\begin{array}{l}\text { Acutely inflamed } \\
(n=63)\end{array}$ & $3 \%$ & \\
\hline $\begin{array}{l}\text { Functional } \\
(n=79)\end{array}$ & $34 \% \dagger \ddagger$ & $\begin{array}{l}\text { Not acutely inflamed } \\
(n=56)\end{array}$ & $14 \%$ & $\begin{array}{l}46 \% \\
(n=82)\end{array}$ \\
\hline $\begin{array}{l}\text { Comparison } \\
(\mathrm{n}=135)\end{array}$ & $8 \%$ & $\begin{array}{l}\text { Comparison } \\
(n=62)\end{array}$ & $3 \%$ & \\
\hline
\end{tabular}

${ }^{*} \mathrm{p}<0 \cdot 001$ compared with community comparison group;

$\dagger p<0.0001$ compared with community comparison group; $\neq p<0 \cdot(001$ compared with organic group.

Table 5 Proportion of subjects who have experienced a severe event by group and psychiatric illness

\begin{tabular}{|c|c|c|c|c|}
\hline \multicolumn{2}{|l|}{ Gastro-Clinic } & \multicolumn{2}{|l|}{ Appendicectomy } & $\mathrm{DSH}$ \\
\hline \multicolumn{5}{|l|}{ Psychiatric } \\
\hline $\begin{array}{l}\text { Organic } \\
(n=56)\end{array}$ & $67 \% 17 \%$ & Acutely inflamed & $40 \% 25 \%$ & \\
\hline $\begin{array}{l}\text { Functional } \\
(n=79)\end{array}$ & $70 \% 65 \%$ & Not acutely inflame & d $78 \% 53 \%$ & $68 \% 73 \%$ \\
\hline $\begin{array}{l}\text { Comparison } \\
(n=135)\end{array}$ & $64 \% 11 \%$ & Comparison & $40 \% 16 \%$ & \\
\hline
\end{tabular}

ence of a severe life event is related to the onset of psychiatric illness, Table 5 presents the results for those subjects with and without psychiatric disorder separately. The patients with organic illness and the community comparison subjects showed the expected pattern, namely those with psychiatric disorder were more likely to have experienced a severe event than the remainder. But for those with functional abdominal pain, like those who had been admitted after deliberate self-harm, even among those who did not have psychiatric disorder the majority had experienced a severe life event. 


\section{Discussion}

These three studies were conducted independently and the results have been presented together to illustrate the patterns of environmental stresses among these different groups of patients. This is only possible because the measures are known to produce reliable results. The samples drawn from surgical wards and gastroenterology clinics were not identical on demographic factors; the appendicectomy and self-poisoning studies selected patients within a narrow age range whereas the gastroenterology clinic study included older patients. This is one reason why the prevalence of psychiatric disorder among the clinic patients is greater than that of the appendicectomy patients.

The prevalence of psychiatric illness in the functional abdominal pain patients in the clinic is slightly lower than that of other studies. ${ }^{50}$ This is because we have only quoted figures for those patients whose psychiatric symptoms preceded the abdominal pain so the former cannot be regarded as a response to chronic pain. To measure this accurately, however, it was necessary to select patients with a relatively recent onset of symptoms - nearly twice as many had to be rejected because their gastrointestinal complaint was chronic. Ford et al ${ }^{13}$ also found that the prevalence of psychiatric disorder fell (from $48 \%$ to $31 \%$ ) when they examined separately those patients whose psychiatric disorder had preceded the onset of bowel symptoms.

Patients attending the gastroenterology clinic with irritable bowel symptoms of 10 years duration ${ }^{14}$ cannot be studied by this method without fear that the results become contaminated by life events which occurred after the onset of abdominal pain. It is of interest that chronic difficulties, especially interpersonal ones, have been shown to be present in an unusually high proportion of these patients before the onset of the abdominal symptoms. This lends credence to the suggestion that interpersonal conflicts precede abdominal complaints even for some patients who firmly attribute their personal problems to the pain. ${ }^{15}$

Approximately one third of patients attending hospital clinics with the irritable bowel syndrome have had a normal appendix removed previously, ${ }^{16-18}$ and $55 \%$ of a recent sample of patients with persistent functional abdominal pain had previously undergone appendicectomy without relief of the pain. ${ }^{\circ}$ It has been suggested that the aetiology of abdominal pain when a normal appendix is removed is that of the irritable bowel syndrome ${ }^{1619}$ and half of the not acutely inflamed appendix patients of the present study continued to have abdominal pain during the post-operative year. ${ }^{9}$ So it is likely that similar mechanisms are involved whether the onset of pain is acute, in the right iliac fossa and leads to appendicectomy or less acute and presents to a gastroenterology clinic. Certainly the pattern of life events is strikingly similar.

In order to make deductions about causality, the exact timing of events and illness onset must be established, which is why the LEDS was used. ${ }^{21}$ For those with psychiatric symptoms the earliest stages of depression could lead to the break-up of a close relationship and it is conceivable that early abdominal pain could also lead to the break-up of a close relationship, especially if it led to sexual problems. We have, however, only considered life events and psychiatric disorder that antedated the onset of abdominal pain. Perhaps the appendicectomy study provides the clearest evidence that severe life events did in fact precede the onset of the abdominal pain (which was exactly dated) and few of these young people experienced psychiatric illness.

One other recent study has used the same life events measure in patients with functional abdominal pain. ${ }^{13}$ There are several differences between that study and the present one: (a) Ford and coworkers ${ }^{13}$ used an idiosyncratic set of measures to rate their life events and only included those events which they have previously found to be related to anxiety. They excluded those types of events which have been related to depression, including two such classes of events (CLHT and CUH) which include marital problems. ${ }^{21}$ Because our study has shown the importance of marital problems among patients with functional bowel disorders, it seems that Ford et al excluded an important group of life events. (b) For those events that Ford et al did include, there was a suggestion that the experience of patients with functional and organic GI disorders was not identical. Equal proportions of these groups had experienced anxiety provoking situations, but the weighted scores for the functional group was twice that of the organic group $(1.6 v 0.8)$. Although this result was not statistically significant in Ford's sample it is in line with our own finding that the difference between organic and functional groups lies in the experience of severe events, rather than in all types of events. (c) Ford et al presented their main results for life events during the six months before the interview - that is, around the time of referral by the GP, rather than at the time of onset of bowel symptoms. This led them to the conclusion that anxiety provoking situations were only important in those patients who also had psychiatric illness. In fact their results concerning psychosocial factors before onset of functional bowel symptoms contradicted this conclusion: $15 / 48(31 \%)$ had experienced psychiatric illness before the onset of bowel symptoms and $17 / 48(35 \%)$ had experienced 
an anxiety provoking situation and only one patient fell into both categories (total figure: $31 / 48-65 \%$ ). Thus anxiety provoking situations and psychiatric disorder appeared to form separate categories of abnormality before onset of bowel disorder, but the interview period did not extend far enough back to see whether the psychiatric disorder had been preceded by a life event. This illustrates the importance of examining the timing of psychosocial precipitants and the onset of bowel symptoms with extreme care.

The similarity of the pattern of life events between the functional abdominal pain patients and the selfpoisoning subjects of our own study was very striking. Only half of the latter had psychiatric symptoms of a severity and duration that merit the diagnosis of psychiatric illness, the remainder had more transient distress. Such a level of distress may also occur in those with functional abdominal pain and play a part in the aetiology of the abdominal pain.

The ways in which severe events may lead to patients presenting with functional abdominal pain are somewhat speculative at present. There is experimental evidence, however, that emotional stress can alter colonic motility, ${ }^{22-24}$ so the experience of a severe life event may lead to painful contractions of the colon in those who are constitutionally predisposed to develop them.

In addition, where psychiatric symptoms are present, depression or anxiety may lead to a lowered pain threshold and this may contribute to the experience of abdominal pain. This explanation would be compatible with the finding that psychological rather than physical treatment may relieve the pain. ${ }^{25} 26$

Alternatively, it may be that the experience of a severe life event, and/or the development of psychiatric symptoms produces treatment seeking behaviour. It is known that there are subjects in the community who experience abdominal pain but who do not consult a doctor for treatment. ${ }^{27-24}$ After the break-up of a close relationship, or a similarly distressing experience, a person with such abdominal pain may seek treatment which she previously thought unnecessary. This explanation would seem to be more appropriate for those attending the gastroenterology clinic than those with a normal appendix removed, but even some of the latter subjects reported previous acute episodes of similar pain for which they had not received treatment, and they have been recorded as showing high levels of illness behaviour. ${ }^{31-31}$

It is notable that marked, long standing relationship difficulties were slightly more common among the gastroenterology clinic patients than the selfpoisoning patients. If such problems, usually marital ones, do not resolve they may explain why functional abdominal pain often becomes chronic. Perhaps early detection of such personal problems and clarification of their relationship with the abdominal pain might help to prevent the chronic somatisation of emotional difficulties that are commonly found in gastroenterology clinics.

Some patients readily admit that their bowel symptoms are exacerbated by stress; direct questions regarding family, marital, and sexual relationships are warranted in the light of the findings reported here and in a quite separate study. ${ }^{32}$ Careful enquiry regarding the date of onset of symptoms (or their exacerbation) and the date of emotional crises may clarify the situation for both the patient and the doctor. For those patients who deny any psychosocial problems further investigations for possible organic illness might be accompanied by further investigations of personal relationships usually involving an interview with the spouse or possibly referral to a psychiatrist. Such referral is facilitated when, during the first interview, the gastroenterologist has shown that he is interested in the patient's social relationships and emotional state as well as organic disease. ${ }^{3 .}$

\section{References}

1 Ferguson A, Sircus W, Eastwood MA. Frequency of 'functional' gastrointestinal disorders. Lancet 1977; ii: 613-4.

2 Swarbrick ET, Hegarty JE, Bat L, Williams CB, Dawson AM. Site of pain from the irritable bowel. Lancet 1980; ii: 443-6.

3 Thompson WG. The irritable bowel. Gut 1984; 25: 305-20.

4 Creed FH, Guthrie E. Psychological factors and the irritable bowel syndrome. Gut 1987; 28: 130718.

5 Macdonald AJ, Bouchier PAD. Non-organic gastrointestinal illness: a medical and psychiatric study. $\mathrm{Br} J$ Psychol 1980; 136: 276-83.

6 Kingham JGC, Dawson AM. Origin of chronic right upper quadrant pain. Gut 1985; 26: 783-8.

7 Brown GW, Harris T. Social origins of depression. London: Tavistock, 1978.

8 Wing JK, Cooper JE, Sartorius N. The measurement and classification of psychiatric symptoms: an instruction manual for the present state examination and CATEGO programme. London: Cambridge University Press, 1974.

9 Creed FH. Life events and appendicectomy. Lancet 1981; i: 1381-5.

10 Donnan SPB, Lambert PM. Appendicitis: incidence and mortality. Population Trends 1976; 5: 26-8.

11 Craig TK, Brown GW. Goal frustration and life events in the aetiology of painful gastrointestinal disorder. J Psychosom Res 1984; 28: 411-21.

12 Farmer $\mathrm{R}$. The role of life events in deliberate selfpoisoning. University of Belfast: Thesis, 1986.

13 Ford MJ, Miller PMcC, Eastwood J, Eastwood MA. Life events, psychiatric illness and the irritable syndrome. Gut 1987; 28: 160-5. 
14 Waller SL, Misiewicz JJ. Prognosis in irritable bowel syndrome. Lancet 1969; ii: 753-6.

15 Bouchier IAD, Mason CM. A study of patients with abdominal symptoms of undefined cause. Scot Med J 1979; 24: 199-205.

16 Chaudhury NA, Truelove SC. The irritable colon syndrome. QJ Med 1962; 31: 307-22.

17 Lane D. The irritable colon and right iliac fossa pain. Med J Austr 1973; 1: 66-7.

18 Keeling PWN, Fielding JF. The irritable bowel syndrome: a review of 50 consecutive cases. J Irish Coll Phys Surg 1975; 4: 91-4.

19 Ingram PW, Evans G, Oppenheim AN. Right iliac fossa pain in young women. $\mathrm{Br}$ Med $J$ 1965; ii: 149-51.

20 Bass C. Life events and gastro-intestinal symptoms. Gut 1986; 27: 123-6.

21 Miller PMcC, Ingham JG. Dimensions of experience and symptomatology. J Psychosom Res 1985; 29: 475-88.

22 Almy TP. Experimental studies on the irritable colon. Am J Med 1951; 10: 60-7.

23 Chaudhury NA, Truelove SC. Human colonic motility: a comparative study of normal subjects, patients with ulcerative colitis, and patients with irritable colon syndrome. Gastroenterology 1961; 40: 27-36.

24 Wangel AE, Deller DJ. Intestinal motility in man. III. Mechanism of constipation and diarrhoea with particular reference to irritable colon syndrome. Gastroenterology $1964 ;$ 48: 69-84.
25 Whorwell PJ, Prior A, Faragher EB. Hypnotherapy in irritable syndrome. Lancet 1984; ii: 1232-4.

26 Svedlund J. Psychotherapy in irritable bowel syndrome. A controlled outcome study. Acta Psychiatr Scand 1983; 67: suppl 306: 1-86.

27 Sandler RS, Drossman DA, Nathan HP, McKee DC. Symptom complaints and health care seeking behaviour in subjects with bowel dysfunction. Gastroenterology 1984; 87: 314-8.

28 Whitehead WE, Winget C, Fedoravicius AS, Wooley S, Blackwell B. Learned illness behaviour in patients with I.B.S. and peptic ulcer. Dig Dis Sci 1982; 27: 202-8.

29 Thompson WG, Heaton KW. Functional bowel disorders in apparently healthy people. Gastroenterology 1980; 79: 283-8.

30 Canton G, Santonastaso P, Fraccon IG. Life events, abnormal illness behaviour and appendectomy. Gen Hosp Psychiatry 1984; 6: 191-5.

31 Joyce PR, Bushell JA, Walshe JWB, Morton JB. Abnormal illness behaviour and anxiety in acute non-organic abdominal pain. Br J Psychol 1986; 149: $57-62$.

32 Guthrie E, Creed FH, Whorwell PJ. Severe sexual dysfunction in patients with the irritable bowel syndrome; a comparison study with inflammatory bowel and peptic ulcer disease. $\mathrm{Br}$ Med J 1987; 295: 577-8.

33 Creed FH, Lennard-Jones JE. Gastrointestinal symptoms. In: Creed FH, Pfeffer JM, eds. Medicine and psychiatry. London: Pitman, 1982: 329. 